\title{
Development and In-House Validation of a Real-Time Polymerase Chain Reaction for the Detection of Listeria monocytogenes in Meat
}

\author{
Camilo Reyes,' Luciano H. Linares, Fabiana Moredo,' Juan P. Lirón,' Victoria Brusa,,2 \\ Alejandra Londero, Lucía Galli, Juan M. Oteiza, Magdalena Costa, and Gerardo A. Leotta ${ }^{1}$
}

\begin{abstract}
Listeriosis is a foodborne disease caused by Listeria monocytogenes. The aims of this work were to develop and validate an in-house real-time polymerase chain reaction (RT-PCR) for the detection of L. monocytogenes, and to determine its prevalence in raw ground beef samples from 53 butcheries that also sell ready-to-eat foods. One set of primers and one hydrolysis probe were designed for hly gene detection and then challenged with pure strains. The detection was successful for all $L$. monocytogenes strains analyzed and negative for all non- $L$. monocytogenes strains (detection limit, 10 colony forming unit $[\mathrm{CFU}] / \mathrm{mL}$ ). Inclusivity, exclusivity, and analytical accuracy were $100 \%$. L. monocytogenes was detected in $41.5 \%$ of raw ground beef samples from the 53 butcheries analyzed. This RT-PCR may be a valuable method for rapid detection of L. monocytogenes in meat.
\end{abstract}

Keywords: Listeria, detection, RT-PCR, validation, meat

$\mathbf{T}$ HE DISEASE CAUSED BY Listeria monocytogenes can range from a mild febrile illness to a systemic (invasive) listeriosis. Raw meat can be a source for L. monocytogenes dissemination in the environment of retail markets or consumers' kitchens, and can cause cross-contamination with ready-to-eat (RTE) products (Luo et al., 2017). Traditional methodologies to search for L. monocytogenes in food are sensitive and remain the "gold standard" as compared with other methods (Gasanov et al., 2005). However, real-time polymerase chain reaction (RT-PCR) is being increasingly applied for the detection of L. monocytogenes in food (Junge et al., 2012). The aims of this work were, therefore, (1) to develop and validate an in-house RT-PCR to detect $L$. monocytogenes and (2) to determine L. monocytogenes prevalence with the RT-PCR developed in raw ground beef samples from 53 butcheries that also sell RTE foods.

One set of primers and one hydrolysis probe were designed for hly gene detection (encoding the pore-forming cytolysin listeriolysin). The DNA sequences of hly from L. monocytogenes strains were recovered from GenBank and aligned using PriSM software (Broad Institute, Cambridge, MA). For the design, a conserved sequence region was selected, based on multiple alignments of the genes using Primer Express 3.0 software. The primer and hydrolysis probe sequences designed were $\left(5^{\prime}-3^{\prime}\right)$ : Forward CACAAGTGGTAAGTTCCGGTCA, Reverse TTGCCAGGTAACGCGAGAAA, and Probe FAMCCGTTCTCCACCATTCCCAAGC-3IABkFQ. All primers and probes were purchased from Integrated DNA Technologies (IDT, Coralville, IA).

The RT-PCR designed was challenged with 12 L. monocytogenes strains, 3 Listeria seeligeri, 3 Listeria welshimeri, and 3 Listeria innocua strains. The detection was successful for all $L$. monocytogenes strains analyzed and negative for all non- $L$. monocytogenes strains. To define the limit of detection (LOD), DNA of 12 L. monocytogenes strains at $10^{1}$ to $10^{4}$ colony forming unit (CFU) was analyzed. LOD was $10 \mathrm{CFU} / \mathrm{mL}$ for all strains, consistent with a previous report (Gattuso et al., 2014). Robustness was determined by the amplification of DNA extracts from tubes containing $10^{2} \mathrm{CFU} / \mathrm{mL}$ of $12 \mathrm{~L}$. monocytogenes strains, in three alternate days and by two operators with different training level. The same results were obtained when the previously mentioned variables were introduced.

\footnotetext{
${ }^{1}$ IGEVET_-Instituto de Genética Veterinaria "Ing. Fernando N. Dulout" (UNLP-CONICET, La Plata), Facultad de Ciencias Veterinarias, UNLP, La Plata, Argentina.

${ }^{2}$ Laboratorio de Microbiología de los Alimentos, Facultad de Ciencias Veterinarias, Universidad Nacional de La Plata, La Plata, Argentina.

${ }^{3}$ Cátedra de Microbiología, Facultad de Ciencias Veterinarias, UNLP, La Plata, Argentina.

${ }^{4}$ Laboratorio de Microbiología de los Alimentos, Centro de Investigación y Asistencia Técnica a la Industria (CIATI AC)-CONICET, Neuquen, Argentina.
} 
Table 1. Strains Used fOR Exclusivity Assay of Real-Time Polymerase Chain Reaction

\begin{tabular}{ll}
\hline Bacterial species & \multicolumn{1}{c}{ Bacterial species } \\
\hline Pseudomona aeruginosa & Proteus mirabilis \\
Yersinia enterocolitica & S. flexneri \\
Shigella sonnei & Proteus vulgaris \\
Salmonella enterica & E. coli (enteropathogenic) \\
$\quad$ serovar Enteritidis & Shigella dysenteriae \\
Shigella flexneri & Morganella morgnaii \\
Edwardsiella tarda & E. coli (enterotoxigenic) \\
Salmonella enterica & Salmonella enterica serovar \\
$\quad$ serovar Dublin & Senftenberg \\
Salmonella enterica & Salmonella enterica serovar \\
$\quad$ serovar Meleagridis & Typhimurium \\
Escherichia coli & Klebsiella pneumoniae \\
& E. coli \\
S. flexneri & \\
Salmonella enterica & Hafnia alvei \\
$\quad$ serovar Derby & Enterobacter cloacae \\
E. coli (enteroaggregative) & Shigella dysenteriae \\
P. aeruginosa & E. coli (enterohemorrhagic) \\
E. coli (enteroinvasive) &
\end{tabular}

These strains were used to determine the ability to not detect Listeria monocytogenes.

For RT-PCR validation, 43 strains of L. monocytogenes and 30 strains of non-L monocytogenes (Table 1) belonging to the collection of IGEVET (Instituto de Genética Veterinaria "Ing. Fernando Noel Dulout"; UNLP-CONICET) were used. They were stored at $-70^{\circ} \mathrm{C}$ and grown in $4 \mathrm{~mL}$ brain heart infusion broth (Biokar, Zac de Ther, France) at $37 \pm 1^{\circ} \mathrm{C}$ for $18-24 \mathrm{~h}$. Serial strain dilutions were performed in buffered peptone water (Biokar) and the inoculum level was confirmed by plating on plate count agar (Britania, BA, Argentina). Plates were incubated at $37^{\circ} \mathrm{C}$ for $18-24 \mathrm{~h}$. DNA extraction was made according to Leotta et al. (2005). The reaction mixture contained $10 \mu \mathrm{L}$ of Master mix qPCR Probe (PB-L, Buenos Aires, Argentina), $0.4 \mu \mathrm{L}$ of $10 \mu \mathrm{M}$ of each forward and reverse primers, $0.2 \mu \mathrm{L}$ of $100 \mu \mathrm{M}$ probe, and $4 \mu \mathrm{L}$ of DNA in a final volume of $20 \mu \mathrm{L}$. Strain ATCC 19115 and molecular biology grade water were included as external positive and no-template control in each run. Cycling used was initial hot-start step at $95^{\circ} \mathrm{C}$ for $3 \mathrm{~min}$, followed by 40 cycles of a denaturation step at $95^{\circ} \mathrm{C}$ for $15 \mathrm{~s}$ and an annealing/extension step at $60^{\circ} \mathrm{C}$ for $30 \mathrm{~s}$. Fluorescence was recorded only at the end of the annealing/extension step. The cycle threshold value was $<34$.

A total of 118 portions of $10 \mathrm{~g}$ raw ground beef were obtained from a commercial retail or store, in the same day and confirmed to be L. monocytogenes-free according to ISO 11290-1:1996/Amd.1:2004(E). Serial dilutions of $43 \mathrm{~L}$. monocytogenes strains and 30 non-L. monocytogenes strains (Table 1) were done as described previously. Meat samples were inoculated with $10(n=43)$ and $100(n=43)$ CFU of $L$. monocytogenes per gram, and 30 meat samples were inoculated with $10^{3} \mathrm{CFU}$ of non-L. monocytogenes per gram. Two samples were mock-inoculated with $1 \mathrm{~mL}$ of sterile Half Fraser Broth (HFB) (Becton Dickinson, Le Pont de Claix, France). Then, each sample was pre-enriched in $90 \mathrm{~mL} \mathrm{HFB}$ for $24 \mathrm{~h}$ at $30^{\circ} \mathrm{C}$ and subsequently analyzed according to the reference culture method ISO 11290-1:1996/Amd.1:2004(E) and the in-house developed RT-PCR. DNA extraction was performed by foodproof ${ }^{\circledR}$ Short Prep II (Biotecon Diagnostics, Postdam, Germany) after the pre-enrichment step. Then the PCR analysis was done following the protocol already described. Inclusivity, exclusivity, and analytical accuracy were $100 \%$. These results are in line with other RTPCR methods for L. monocytogenes detection validated in meat products (Garrido et al., 2012; Heo et al., 2014).

L. monocytogenes can multiply at refrigeration temperatures, form biofilms on different materials and under various conditions, and resist a range of environmental stresses (Law et al., 2015). Thus, the presence of this bacterium in retail shop environments is a risk due to the possibility of crosscontamination with food products (Leotta et al., 2016). We, therefore, conducted a field study to apply and validate the RT-PCR developed. Raw ground beef samples from 53 butcheries that also sell RTE foods including cooked products, cheeses, vegetables, and/or cold meats were analyzed. Raw ground beef samples were analyzed according to ISO 11290-1:1996/Amd.1:2004(E) and the RT-PCR developed. L. monocytogenes was simultaneously detected by RT-PCR and isolated from raw ground beef in 22 of the 53 butcheries analyzed $(41.5 \%)$. The prevalence of L. monocytogenes obtained in this study was higher than that reported in Algeria $(8.9 \%)$ and Malaysia $(9.0 \%)$, but lower than that obtained in Turkey (45.0\%) and Brazil (48.7\%) (Du et al., 2017).

The RT-PCR developed showed adequate performance with pure strains, artificially contaminated raw ground beef samples, and naturally contaminated samples. This screening could allow a rapid intervention on contaminated food and the environment where it is produced. Moreover, the short time required to obtain a negative result could allow a fast verification on the procedures of meat and meat products or a fast commercialization of ground beef. In the future, the evaluation of this assay on other food matrices may also extend its application in food safety analyses.

\section{Acknowledgments}

This research was supported by funds from Consejo Nacional de Investigaciones Científicas y Técnicas PIP (20102012) No. 0266. The authors thank Cristian Adriani from the Department of Food Safety, Municipality of Berisso, for his help in sampling at the retail markets. We also thank Adriana Di Maggio for editing the article.

\section{Disclosure Statement}

No competing financial interests exist.

\section{References}

Du X, Zhang X, Wang X, Su Y, Li P, Wang S. Isolation and characterization of Listeria monocytogenes in Chinese food obtained from the central area of China. Food Control 2017;74:9-16.

Garrido A, Chapela MJ, Román B, Ferreira M, Lago J, Vieites JM, Cabado AG. Development of a multiplex real-time PCR method for simultaneous detection of Salmonella enterica, Shigella flexneri and Listeria monocytogenes in processed food samples. Eur Food Res Technol 2012;234:571-580. 
Gasanov U, Hughes D, Hansbro PM. Methods for the isolation and identification of Listeria spp. and Listeria monocytogenes: A review. FEMS Microbiol Rev 2005;29:851875.

Gattuso A, Gianfranceschi MV, Sonnessa M, Delibato E, Marchesan M, Hernandez M, De Medici D, RodriguezLazaro D. Optimization of a Real Time PCR based method for the detection of Listeria monocytogenes in pork meat. Int J Food Microbiol 2014;184:106-108.

Heo EJ, Song BR, Park HJ, Kim YJ, Moon JS, Wee SH, Kim JS, Yoon Y. Rapid detection of Listeria monocytogenes by real-time PCR in processed meat and dairy products. J Food Prot 2014;77:453-458.

Junge B, Grönewald C, Berghof-Jäger K. BIOTECON diagnostics foodproof Listeria monocytogenes Detection Kit, 5' nuclease in combination with the foodproof ShortPrep II Kit. J AOAC Int 2012;95:92-99.

Law JW, Ab Mutalib NS, Chan KG, Lee LH. An insight into the isolation, enumeration, and molecular detection of Listeria monocytogenes in food. Front Microbiol 2015;6:1227.

Leotta GA, Brusa V, Galli L, Adriani C, Linares L, Etcheverría A, Sanz M, Sucari A, Peral García P, Signorini M. Com- prehensive evaluation and implementation of improvement actions in butcher shops. PLoS One 2016;11:e0162635.

Leotta GA, Chinen I, Epszteyn S, Miliwebsky E, Melamed IC, Motter M, Ferrer M, Marey E, Rivas M. Validación de una técnica de PCR múltiple para la detección de Escherichia coli productor de toxin shiga. Rev Arg Microbiol 2005;37:1-10.

Luo L, Zhang Z, Wang H, Wang P, Lan R, Deng J, Miao Y, Wang Y, Wang Y, Xu J, Zhang L, Sun S, Liu X, Zhou Y, Chen X, Li Q, Ye C. A 12-month longitudinal study of Listeria monocytogenes contamination and persistence in pork retail markets in China. Food Control 2017;76:66-73.

Address correspondence to:

Gerardo A. Leotta, PhD

IGEVET-Instituto de Genética Veterinaria

“Ing. Fernando N. Dulout" (UNLP-CONICET LA PLATA)

Facultad de Ciencias Veterinarias, UNLP

Av. 60 y 118, CC 296

La Plata 1900

Argentina

E-mail: gerardo.leotta@gmail.com 